\title{
BMJ Open Proximal deep vein thrombosis among hospitalised medical and obstetric patients in Rwandan university teaching hospitals: prevalence and associated risk factors: a cross-sectional study
}

\author{
Regine Mugeni (D) , ${ }^{1}$ Eugene Nkusi, ${ }^{2}$ Eric Rutaganda, ${ }^{3,4}$ Sanctus Musafiri, ${ }^{3,4}$ \\ Florence Masaisa, ${ }^{3,4}$ Kayan Lea Lewis, ${ }^{5}$ Marc Simpao, ${ }^{6}$ \\ Pierrot Lundimu Tugirimana, ${ }^{7}$ Timothy David Walker (1) ${ }^{8,9}$
}

To cite: Mugeni R, Nkusi E, Rutaganda $\mathrm{E}$, et al. Proximal deep vein thrombosis among hospitalised medical and obstetric patients in Rwandan university teaching hospitals: prevalence and associated risk factors: a crosssectional study. BMJ Open 2019;9:e032604. doi:10.1136/ bmjopen-2019-032604

- Prepublication history for this paper is available online To view these files, please visit the journal online (http://dx.doi. org/10.1136/bmjopen-2019032604).

Received 29 June 2019 Revised 26 September 2019 Accepted 29 0ctober 2019

Check for updates

(C) Author(s) (or their employer(s)) 2019. Re-use permitted under CC BY-NC. No commercial re-use. See rights and permissions. Published by BMJ.

For numbered affiliations see end of article.

Correspondence to Dr Regine Mugeni; pacisreg@gmail.com

\section{ABSTRACT}

Objectives To determine the prevalence of proximal deep vein thrombosis (DVT) by ultrasound scanning, as well as associated clinical features and known risk factors, among medical and obstetrics-gynaecology inpatients in two Rwandan tertiary hospitals.

Design Cross-sectional study.

Settings Rwanda teaching hospitals: Kigali and Butare University Teaching Hospitals.

Participants 901 adult patients admitted to the Departments of Internal Medicine and ObstetricsGynecology $(0 \& G)$ who were at least 21 years of age and willing to provide a consent.

Outcomes Prevalence of proximal DVT, clinical features and known risk factors associated with DVT.

Methods Between August 2015 and August 2016, participants were screened for DVT by compressive ultrasound of femoral and popliteal veins, conducted as a monthly cross-sectional survey of all consenting eligible inpatients. Patients completed a self-report survey on DVT risk factors. Prevalence of proximal DVT by compression ultrasonography was the primary endpoint, with univariate and multivariate regression analyses performed to assess associated clinical features and risk factors.

Results Proximal DVT was found in $5.5 \%$ of the study population, with similar rates in medical and $0 \& \mathrm{G}$ inpatients. The mean age was $41 \pm 16 \mathrm{SD}$ (range, 21-91), 70\% were female and $7 \%$ were pregnant. Univariate analysis showed active malignancy, immobilisation, prolonged recent travel and history of DVT to be significant risk factors for proximal DVT (all $p$ values $<0.05$ ); while only active malignancy was an independent risk factor on multivariate regression (OR $5.2 ; 95 \% \mathrm{Cl} 2.0$ to 13). Leg pain or tenderness, increased calf circumference, unilateral limb swelling or pitting oedema were predictive clinical features of DVT on both univariate analysis and multivariate regression (all $p$ values $<0.05$ ). Conclusion Proximal DVT prevalence is high among hospitalised medical and 0\&G patients in two tertiary hospitals in Rwanda. For reducing morbidity and mortality, research to develop Africa-specific clinical prediction tools for DVT and interventions to increase thromboprophylaxis use in the region are urgently needed.
Strengths and limitations of this study

- This cross-sectional study described deep vein thrombosis (DVT) point prevalence and associated clinical features and known risk factors among 901 medical and obstetrics-gynaecology inpatients in two Rwandan tertiary hospitals.

- DVT prevalence was determined by compression ultrasonography, performed by trained junior medical staff, with confirmation of all positive compression scans by a radiologist.

- Clinical features of interest were determined by a structured patient history and physical examination and review of the medical record.

- Due to the location of the study in Rwanda, there was no access to venography, the preferred gold standard for confirming DVT.

\section{BACKGROUND}

Deep vein thrombosis (DVT) is a condition characterised by one or more blood clots forming in a deep vein, commonly in the leg or pelvis. DVT clots may migrate to the lungs, causing pulmonary embolism ${ }^{1-3}$ and such venous thromboembolism (VTE) is the leading cause of preventable inpatient morbidity and mortality. ${ }^{3}$ The annual incidence in adults worldwide of a first VTE is 1-2 events per 1000 patient years ${ }^{4}$ and approximately 1 per 1000 adult patients suffers a clinically diagnosable event. ${ }^{5}$ VTE appears more common in Europe and the USA than in Asia and Africa. ${ }^{6}$ VTE is associated with bed rest or immobility and affects patients hospitalised for both medical and surgical conditions. ${ }^{78}$ Among surgical inpatients, DVT affects a proportion as high as $35 \%$ in Western countries, $12 \%$ in Malaysia, $9.6 \%$ in Sudan and $2.9 \%$ in Nigeria. ${ }^{69}$ The 
incidence of VTE varies from $5 \%$ to $30 \%$ among general medical patients. ${ }^{10}$ Pregnant women are more susceptible to VTE, the risk of VTE is higher in a pregnant woman than in a non-pregnant woman of the same age and the risk has also been shown to be higher in the postpartum period. ${ }^{11} 12$ Although there are some data from Nigerian and Sudanese populations during pregnancy and the postpartum period, ${ }^{9}$ no prior published data regarding the epidemiology, risk factors and diagnosis of DVT in the East African region were identifiable by our literature search.

Three aetiological factors are involved in thrombosis: vascular endothelial damage, stasis of blood flow and hypercoagulability. ${ }^{13}$ Among the patients treated for VTE, $96 \%$ have been recognised to have at least one risk factor and hypercoagulability accounts for most spontaneous DVTs. ${ }^{1}$ Recognised risk factors include increasing age, prolonged immobility, malignancy, major surgery, trauma, prior VTE, hormone use, obesity, chronic heart failure, nephrotic syndrome, inflammatory bowel disease and myeloproliferative disorders as well as pregnancy and the postpartum period. ${ }^{514}$ In addition, admissions with acute infection have been associated with an increased risk for DVT. ${ }^{15}$ Admissions to sub-Saharan African medical and obstetric wards include many patients with serious infections, but patients are generally younger and illness behaviour may be different, with many unwell patients remaining ambulant. In these settings, illness severity is high and mechanical and pharmacological thromboprophylaxis is rare, leading to uncertainty about whether data from other parts of the world should be extrapolated to this context.

This study proposed to assess proximal DVT burden among hospitalised patients in the Internal Medicine and Obstetrics-Gynecology Departments in two tertiary care teaching hospitals in Rwanda. The objectives were to determine the prevalence of proximal DVT among medical, and obstetrics-gynaecology inpatients, to determine the clinical features and associated known risk factors for these DVTs, and to estimate the magnitude of risk associated with each factor.

\section{METHODS}

\section{Study design and site description}

This cross-sectional, multicentre survey evaluated patients admitted to the Departments of Internal Medicine and Obstetrics and Gynecology in two tertiary care teaching hospitals in Rwanda, Kigali University Teaching Hospital (Centre Hospitalier Universitaire de Kigali: CHUK) and Butare University Teaching Hospital (Centre Hospitalier Universitaire de Butare: CHUB). CHUK and CHUB are publicly funded hospitals located in Kigali the Capital City and the Southern Province, respectively.

\section{Study population}

Between 1 August 2015 and 30 August 2016, all patients admitted in the medical, and obstetrics and gynaecology wards at CHUB and CHUK who were at least 21 years of age, had been admitted for $\geq 3$ days, and were willing and able to provide informed consent on the monthly day of enrolment were recruited.

Given the lack of prior local studies in the study population, the prevalence of symptomatic DVT was estimated based on a Sudanese study in an obstetric population with DVT prevalence of $0.5 \% .{ }^{11}$ In several studies, the rate of asymptomatic DVT was approximately 10 times higher than the symptomatic rate giving an estimated prevalence of $5 \%$ for asymptomatic DVT. A similar figure of $5 \%$ for asymptomatic DVT was also obtained from a French study in a hospitalised population. ${ }^{17}$ Based on a large eligible population (hospitalised medical and obstetric-gynaecology patients in Rwanda), and assuming the estimated asymptomatic DVT prevalence is $5 \%$, a sample size of 454 was calculated to achieve a $1 \%$ absolute SE in the rate of DVT at a $95 \%$ confidence level. To ensure adequate power to analyse risk factors and prediction modelling, the target sample size was doubled (908 patients). A total of 933 patients were approached for enrolment in the study and 17 withheld consent, meaning 916 patients were enrolled. Among these enrolled patients, 15 patients were not included in analysis due to incomplete data for the primary outcome, leaving 901 patients for analysis.

\section{Data collection}

To ensure consistency in enrolment and enable study logistics to occur, on the third and fourth Thursdays and Fridays of each month, all patients admitted to the Obstetrics and Gynecology and Medical wards at CHUB and CHUK were screened for eligibility (ie, one screening day per ward per month). If consent was obtained, patients were enrolled in the study and demographic characteristics were recorded: patient hospital identification, sex, date of birth and hospital location. In addition, clinical characteristics were obtained by chart review or bedside survey, both focused history and clinical examination of the lower extremities. These included the clinical features or factors previously employed in published risk assessment models such as the Wells and Padua scores. ${ }^{16} 18$

Clinical features included symptoms and signs of DVT: pain and/or tenderness of the lower limb(s); tenderness along the line of femoral or popliteal veins; increased calf circumference more than $3 \mathrm{~cm}$; swelling of the entire lower limb; unilateral limb pitting oedema; dilated superficial collateral (non-varicose) veins. The risk factors included a history of being immobilised (complete bed rest or inability to walk for $>30 \mathrm{~min}$ per day) for more than 3 days, surgery within the last 4 weeks, lower limb trauma, recent travel $>6$ hours, congestive cardiac failure, respiratory failure, recent stroke ( $<3$ months), acute infectious disease and a history of confirmed VTE. Other medical conditions associated with DVT recorded included inflammatory bowel disease, malignancy (presently or previously on active or palliative treatment within the last 6 months), myeloproliferative syndrome, nephrotic syndrome and chronic venous insufficiency. ${ }^{14}{ }^{19}$ The 
patient's clinical information related to pregnancy and the puerperium, and oral contraceptive pill (OCP) use were also collected for women. Additional information that was collected from the patient chart included use of DVT prophylaxis, and height and weight, allowing calculation of body mass index (BMI).

After the collection of all demographic and clinical information, a well-trained research doctor performed a compression ultrasound (US) of the bilateral lower extremities for each study participant. A Sonosite M-Turbo ultrasound machine was used for compression of veins in both legs at the level of the femoral and popliteal veins, using a vascular $\mathrm{L} 38 / 10-5 \mathrm{~Hz}$ probe with firm compression. Patient was positioned with each leg externally rotated at the hip and slightly flexed at the knee, and the probe was transversally directed on the proximal femoral triangle, starting near the inguinal ligament, so that the common femoral vein and artery could be well visualised. Firm compression and pressure release were applied alternately to the vein, with the operator then sliding the probe distally to follow the great saphenous vein and the bifurcation of the common femoral vein into the superficial and deep femoral veins, before scanning shifted to the popliteal fossa, to scan popliteal vein until it trifurcates. A study was considered positive in the case of the absence of complete venous compressibility at any location. $^{20}$

Positive studies were then confirmed by an experienced hospital radiologist at each study site according to their usual practice, involving a formal US scan with both compression and Doppler studies. The primary study outcome was proximal DVT, defined as a DVT in either femoral or popliteal veins on compressive USs by both the research doctor and the radiologist. Research doctors were three senior internal medicine residents who underwent a multiday training course conducted by a team from the Point of care Ultrasound in Resource-limited Environments (PURE) Initiative in performing bedside DVT compression US. ${ }^{21}$

\section{Statistical analysis}

The data were initially entered on paper data collection forms and then transferred into Epidata (V.2.0.85.6) software. Data analysis was performed using STATA (V.14; StataCorp, College Station, Texas, USA). Prevalence was calculated with the numerator being confirmed DVT cases and the denominator being all screening episodes across all study sites over the study period (ie, per episode not per patient). Patients providing incomplete data were included in the analysis as long as data were available for the primary outcome. Demographic and clinical characteristics were evaluated and presented as mean $\pm \mathrm{SD}$ for continuous variables and frequencies (percentage) for categorical variables. $\chi^{2}$ was used for categorical variables. Statistical significance was defined as a $\mathrm{p}$ value $<0.05$. Multivariate logistic regression was performed for all variables found significant on univariate analysis, with a $\mathrm{p}$ value $<0.05$ and an absolute frequency $>5$.

\section{Ethical consideration}

For patients unable to provide written consent due to their medical condition or altered mental status, direct family members provided delegated consent on their behalf. Positive DVT studies on US were communicated to patients and to their treating teams on the day of scanning for initiation of immediate management.

\section{Patient and public involvement}

Patients and the public were not involved in the design, conduct or analysis of this study.

\section{RESULTS \\ Socio-demographic and baseline characteristics of study participants}

Among 916 medical and obstetrics-gynaecology patients eligible and consenting to study participation, a total of 901 patients completed screening for DVT at the two referral teaching hospitals (CHUB and CHUK) between August 2015 and August 2016. The mean age was $41 \pm 16$ years (range, 21-91), with the majority $(57 \%, 513 / 901)$ between the ages of 20 and 39 years. Women made up $70.1 \%(632 / 901)$ and $65.1 \%(587 / 901)$ of the study participants were from medical wards. Among the women, $7 \%$ (44/632) were pregnant, while $29 \%(185 / 632)$ were in the postpartum period. In addition, 17.1 (154/901) of the study population had an active or recent malignancy and $31 \%(281 / 901)$ had acute infectious disease. Also, $80.4 \%(694 / 863)$ of the population had a normal BMI and $11.1 \%(96 / 863)$ were in underweight range. Of all enrolled patients, 6.3\% (57/901) were on DVT prophylaxis (see table 1 for details).

\section{DVT prevalence, clinical features or risk factors associated with DVT}

Among 901 patients enrolled, the prevalence of DVT was $5.5 \%(50 / 901)$. Stratified analysis by location revealed no significantly different DVT prevalence in either medical $(5.4 \%(25 / 382))$ or obstetric-gynaecology $(5.7 \%(15 / 207))$ patients (table 2$)$. A total of 14 patients (28\%) with DVT were on DVT prophylaxis at the time of diagnosis.

Univariate analyses of the relationship between DVT as the primary outcome and known risk factors or potentially predictive clinical features were conducted (table 2 ). Evaluating the rate DVT and sociodemographic factors including age, gender and BMI, the results were not statically significant: by age subgroup analysis, between 40 and 59 years (30/513, referent), 20 and 39 years $(9 / 231$, $\mathrm{p}=0.269)$, and 60 years and above $(11 / 157, \mathrm{p}=0.174)$. There was no significant difference by gender for those with and without DVT (female 36/632, $\mathrm{p}=0.768$ ) as well as BMI categories, from 18 to $25 \mathrm{~kg} / \mathrm{m}^{2}$ (34/694, referent), less than $18 \mathrm{~kg} / \mathrm{m}^{2}(6 / 96, \mathrm{p}=0.571), 25.1$ to $30 \mathrm{~kg} / \mathrm{m}^{2}$ $(4 / 60, \mathrm{p}=0.548)$ and BMI above $30 \mathrm{~kg} / \mathrm{m}^{2}(2 / 13, \mathrm{p}=0.088)$ (table 2). Comparing those with known traditional DVT risk factors and without, the univariate analysis showed 
Table 1 Sociodemographic and clinical characteristics of study participants

\begin{tabular}{|c|c|c|c|}
\hline & $\begin{array}{l}\text { All } \\
\text { patients } \\
\mathrm{n}(\%)\end{array}$ & $\begin{array}{l}\text { Medical } \\
\text { patients } \\
\mathrm{n}(\%)\end{array}$ & $\begin{array}{l}\text { Obstetrics- } \\
\text { gynaecology } \\
\text { patients } \\
\text { n (\%) }\end{array}$ \\
\hline Total population & $901(100)$ & $587(65.1)$ & 314 (34.9) \\
\hline \multicolumn{4}{|l|}{ Gender } \\
\hline Female & $632(70.1)$ & $318(54.2)$ & $314(100)$ \\
\hline Male & 269 (29.9) & $269(45.8)$ & $0(0)$ \\
\hline \multicolumn{4}{|l|}{ Age } \\
\hline Mean $( \pm S D)$ & $41 \pm 16$ & $45 \pm 18$ & $34 \pm 10$ \\
\hline $20-39$ & $513(56.9)$ & $255(43.4)$ & $258(82.2)$ \\
\hline $40-59$ & $231(25.6)$ & $191(32.5)$ & $40(12.7)$ \\
\hline$\geq 60$ & $157(17.4)$ & $141(24)$ & $16(5.1)$ \\
\hline \multicolumn{4}{|l|}{ BMI $\left(k g / m^{2}\right)(n=863)$} \\
\hline$<18$ & $96(11.1)$ & 85 (15.2) & $11(3.7)$ \\
\hline $18-25$ & $694(80.4)$ & $437(77.8)$ & $257(85.4)$ \\
\hline $25.1-30$ & $60(7.0)$ & $31(5.5)$ & $29(9.6)$ \\
\hline$>30$ & $13(1.5)$ & $9(1.6)$ & $4(5.5)$ \\
\hline \multicolumn{4}{|l|}{ Hospital } \\
\hline CHUK & $459(50.9)$ & $308(52.5)$ & $151(48.1)$ \\
\hline CHUB & $442(49.1)$ & $279(47.5)$ & $163(51.9)$ \\
\hline \multicolumn{4}{|l|}{ Clinical variables } \\
\hline Pregnancy ( $n=632$ ) & $44(7.0)$ & $0(0)$ & $44(14.0)$ \\
\hline $\begin{array}{l}\text { Postpartum period } \\
(\mathrm{n}=632)\end{array}$ & $185(29.3)$ & $2(0.6)$ & $183(58.3)$ \\
\hline OCP use ( $n=632)$ & $7(1.1)$ & $5(1.6)$ & $2(0.6)$ \\
\hline History of VTE & $5(0.6)$ & $1(0.2)$ & $4(1.3)$ \\
\hline Known malignancy* & $154(17.1)$ & $118(20.1)$ & $36(11.5)$ \\
\hline Acute infectious disease & $281(31.2)$ & $196(33.4)$ & $85(27.1)$ \\
\hline $\begin{array}{l}\text { Receiving DVT } \\
\text { prophylaxis }\end{array}$ & $57(6.3)$ & $41(7.0)$ & $16(5.1)$ \\
\hline
\end{tabular}

*Malignancy present or previous, on treatment or palliation up to 6 months previously.

BMI, body mass index; CHUB, Centre Hospitalier Universitaire de Butare; CHUK, Centre Hospitalier Universitaire de Kigali; OCP, oral contraceptive pill; VTE, venous thromboembolism.

no significant difference including congestive cardiac failure $(6 / 80, p=0.425)$, history of low limb trauma or surgery $(0 / 30, \mathrm{p}=0.177)$, smoking $(4 / 37, \mathrm{p}=0.153)$, respiratory failure $(3 / 34, \mathrm{p}=0.395)$, stroke $(1 / 46, \mathrm{p}=0.293)$, acute infectious disease $(10 / 281, p=0.08)$, inflammatory bowel disease $(0 / 2, \mathrm{p}=0.731)$ and nephrotic syndrome $(0 / 7, p=0.520)$. In contrast, active malignancy, history of recent travel more than 6 hours and complete immobilisation for more than 3 days were risk factors associated with DVT (18/50, 3/6 and 28/314, respectively; all $\mathrm{p}$ values $\leq 0.0 .001)$ as well as history of confirmed VTE $(2 / 5, p=0.03)$. The following predictive clinical features with their appropriate DVT rate: entire low limb swelling $(40 / 119)$, tenderness along the line of femoral or popliteal veins $(16 / 34)$, increased calf circumference $(15 / 26)$,
Table 2 DVT frequency by compression ultrasonography and univariate association with demographic, clinical and risk factors

\begin{tabular}{|c|c|c|c|}
\hline & DVT n/N (\%) & OR (95\% Cl) & $P$ value \\
\hline Total population & $50 / 901(5.5)$ & NA & \\
\hline \multicolumn{4}{|l|}{ Gender } \\
\hline Female & $36 / 632(5.7)$ & 1.1 (0.15 to 2.2$)$ & 0.768 \\
\hline Male & 14/269 (5.2) & REF & \\
\hline Age mean $\pm S D$ & $41.8 \pm 15.9$ & NA & \\
\hline \multicolumn{4}{|l|}{ Age group } \\
\hline 20-39 & $30 / 513$ (5.9) & 1.5 (0.69 to 3.7$)$ & 0.269 \\
\hline $40-59$ & 9/231 (3.9) & REF & \\
\hline$\geq 60$ & $11 / 157(7)$ & 1.9 (0.68 to 5.2) & 0.174 \\
\hline \multicolumn{4}{|c|}{$\operatorname{BMI}\left(\mathrm{kg} / \mathrm{m}^{2}\right)(\mathrm{n}=863)$} \\
\hline$<18$ & 6/96 (6.3) & 1.3 (0.43 to 3.2$)$ & 0.571 \\
\hline $18-25$ & $34 / 694$ (4.9) & REF & \\
\hline $25.1-30$ & $4 / 60(6.7)$ & $1.4(0.34$ to 4.1$)$ & 0.548 \\
\hline$>30$ & 2/13 (15.4) & 3.5 (0.36 to 17$)$ & 0.088 \\
\hline
\end{tabular}

Admitting

service

$\begin{array}{llll}\text { Medical } & 32 / 587(5.5) & 0.91(0.50 \text { to } 1.8) & 0.856 \\ \text { OBS-GYN } & 18 / 314(5.7) & \text { REF }\end{array}$

Hospital department

\begin{tabular}{|c|c|c|c|}
\hline CHUK_OB & $12 / 151(8.0)$ & 2.3 (0.75 to 7.5$)$ & 0.104 \\
\hline CHUK_IM & $17 / 308$ (5.5) & 1.5 (0.56 to 4.8$)$ & 0.379 \\
\hline CHUB_IM & $15 / 279(5.4)$ & $1.4(0.53$ to 4.8$)$ & 0.419 \\
\hline CHUB_OB & 6/163 (3.7) & REF & \\
\hline \multicolumn{4}{|l|}{ Pregnancy } \\
\hline Yes & 5/44 (11.4) & 2.3 (0.66 to 6.4$)$ & 0.09 \\
\hline No & $31 / 588(5.3)$ & REF & \\
\hline \multicolumn{4}{|c|}{ Postpartum period < 6 weeks } \\
\hline Yes & 6/185 (3.2) & 0.47 (0.15 to 1.2$)$ & 0.09 \\
\hline No & $30 / 447(6.7)$ & REF & \\
\hline \multicolumn{4}{|c|}{ Clinical features } \\
\hline \multicolumn{4}{|c|}{ Pain/tenderness of the lower limb } \\
\hline Yes & $35 / 88(39.8)$ & 35 (17 to 73$)$ & $\leq 0.001^{*}$ \\
\hline No & $15 / 813(1.9)$ & REF & \\
\hline \multicolumn{4}{|c|}{ Calf asymmetry $\dagger$} \\
\hline Yes & $15 / 26(57.7)$ & 33 (13 to 84$)$ & $\leq 0.001^{*}$ \\
\hline No & $35 / 875(4)$ & REF & \\
\hline
\end{tabular}

Entire limb swollen

\begin{tabular}{|c|c|c|c|}
\hline Yes & $40 / 119(33.6)$ & 39 (18 to 90$)$ & $\leq 0.001^{*}$ \\
\hline No & 10/782 (1.3) & REF & \\
\hline \multicolumn{4}{|c|}{ Unilateral limb pitting oedema } \\
\hline Yes & $27 / 41(65.9)$ & 70 (31 to 163$)$ & $\leq 0.001^{*}$ \\
\hline No & $23 / 860(2.7)$ & REF & \\
\hline \multicolumn{4}{|c|}{ Dilated collateral superficial veins } \\
\hline Yes & $5 / 14(35.7)$ & $10(2.6$ to 36$)$ & $\leq 0.001^{*}$ \\
\hline No & $45 / 8875.1)$ & REF & \\
\hline
\end{tabular}

Continued 
Table 2 Continued

DVT $\mathrm{n} / \mathrm{N}(\%) \quad$ OR $(95 \% \mathrm{Cl}) \quad$ P value

Tenderness along line of femoral or popliteal veins

Yes $\quad 16 / 34(47.1) \quad 22$ (9.4 to 49)

No $\quad 34 / 867(4.0) \quad$ REF

Risk factors

Bedridden $\ddagger$

Yes $\quad 28 / 314(8.9) \quad 2.5(1.4$ to 4.5$) \quad \leq 0.001^{*}$

No 22/587 (3.8) REF

Lower limb trauma§

$\begin{array}{llll}\text { Yes } & 0 / 30(0) & \text { NA } & 0.177\end{array}$

Recent smoking (in last 4 weeks)

Yes $\quad 4 / 37(10.8) \quad 2.2(0.73$ to 6.4$) \quad 0.153$

No $46 / 864$ (5.3) REF

Recent travel $>6$ hours

\begin{tabular}{|c|c|c|c|}
\hline Yes & $3 / 6(50)$ & 18 (2.3 to 137$)$ & $\leq 0.001^{*}$ \\
\hline No & 47/895 (5.2) & REF & \\
\hline \multicolumn{4}{|c|}{ Congestive cardiac failure } \\
\hline Yes & 6/80 (7.5) & $1.4(0.48$ to 3.5$)$ & 0.425 \\
\hline No & 44/821 (5.4) & REF & \\
\hline
\end{tabular}

Respiratory failure

\begin{tabular}{|c|c|c|c|}
\hline Yes & $3 / 34(8.8)$ & 1.7 (0.31 to 5.7$)$ & 0.395 \\
\hline No & $47 / 867(5.4)$ & REF & \\
\hline \multicolumn{4}{|c|}{ Recent stroke (<3 months) } \\
\hline Yes & $1 / 46(2.2)$ & 0.36 (0.09 to 2.2$)$ & 0.293 \\
\hline No & $49 / 855(5.7)$ & REF & \\
\hline \multicolumn{4}{|c|}{ Acute infectious disease } \\
\hline Yes & 10/281 (3.6) & $0.53(0.24$ to 1.1$)$ & 0.08 \\
\hline No & $40 / 620(6.5)$ & REF & \\
\hline \multicolumn{4}{|c|}{ History of confirmed VTE } \\
\hline Yes & $2 / 5(40)$ & 12 (1.9 to 72 ) & $0.03^{*}$ \\
\hline No & $48 / 896(5.4)$ & REF & \\
\hline \multicolumn{4}{|c|}{ Inflammatory bowel disease } \\
\hline Yes & $0 / 2(0)$ & NA & 0.731 \\
\hline No & $50 / 899(5.6)$ & & \\
\hline \multicolumn{4}{|c|}{ ףMalignancy } \\
\hline \multirow[t]{2}{*}{ Yes } & $18 / 50$ & $3.0(1.51$ to 5.60$)$ & $\leq 0.001^{\star}$ \\
\hline & $32 / 851$ & & \\
\hline \multicolumn{4}{|c|}{ Nephrotic syndrome } \\
\hline Yes & $0 / 7(0)$ & NA & 0.520 \\
\hline No & $50 / 894(5.6)$ & & \\
\hline \multicolumn{4}{|c|}{ Chronic venous insufficiency } \\
\hline Yes & $0 / 5(0)$ & NA & 0.587 \\
\hline No & $50 / 896(5.6)$ & & \\
\hline \multicolumn{4}{|c|}{ OCPs $(n=632)$} \\
\hline Yes & $0 / 7(0)$ & NA & 0.513 \\
\hline No & $36 / 625$ (5.8) & & \\
\hline
\end{tabular}

Continued
Table 2 Continued

\begin{tabular}{clll} 
& DVT $\mathbf{n} / \mathbf{N}(\%)$ & OR (95\% Cl) & P value \\
\hline Receiving DVT prophylaxis & & \\
Yes & $14 / 57(24.6)$ & $7.3(3.4$ to 15$)$ & $\leq 0.001^{*}$ \\
No & $36 / 851(4.3)$ & REF & \\
\hline
\end{tabular}

*Statistically significant $(p<0.05)$.

†Calf more than $3 \mathrm{~cm}$ different in circumference, $10 \mathrm{~cm}$ below tibial tuberosity.

†Immobilisation (complete bed rest or inability to walk for $>30$ min per day) for $>3$ days.

$\S$ Lower limb trauma or surgery or immobilisation in a plaster cast (in last 4 weeks).

१Malignancy present or previous, on treatment or palliation up to 6 months previously.

BMI, body mass index;CHUB-IM, Internal Medicine Department of Centre Hospitalier Universitaire de Butare; CHUB-OB, Obstetrics and Gynecology Department of Centre Hospitalier Universitaire de Butare; CHUK-IM, Internal Medicine Department of Centre Hospitalier Universitaire de Kigali; CHUK-OB, Obstetrics and Gynecology Department of Centre Hospitalier Universitaire de Kigali; DVT, deep vein thrombosis; NA, not applicable; OBS-GYN, obstetrics and gynaecology departments; OCP, oral contraceptive pill; REF, referent group; VTE, venous thromboembolism.

unilateral limb pitting oedema $(27 / 41)$ and dilated collateral superficial veins $(5 / 14)$, were all significantly associated with DVT $(\mathrm{p} \leq 0.001)$. The known DVT risk factors evaluated among women such as pregnancy (5/44, $\mathrm{p}=0.09)$, being in the postpartum period $(6 / 185, \mathrm{p}=0.09)$ and taking oral contraceptives $(0 / 7, \mathrm{p}=0.513)$ were not significantly associated with DVT.

Multivariate logistic regression was performed for variables found to be significant predictors of DVT on univariate analysis with at least five cases in each group. Active malignancy was the only risk factor independently associated with DVT (OR 5.2; 95\% CI 2.0 to 13) (table 3). Unilateral pitting oedema (OR 7.6; 95\% CI 2.3 to 26), entire limb swelling (OR 10; 95\% CI 4.1 to 24), pain or tenderness of the lower limb (OR 7.0; 95\% CI 2.4 to 20.3) and increased calf circumference (OR 3.6; 95\% CI 1.0 to 12) remained significant clinical features of DVT (all p<0.05) on multivariate analysis (table 3). It is worth noting that for some risk factors, a small sample size limited further statistical interpretation (recent travel $>6$ hours, history of past VTE), despite both having $\mathrm{p}$ values $<0.05$ on univariate analysis.

\section{DISCUSSION}

This study aimed to determine the prevalence of DVT among hospitalised medical and obstetrics-gynaecology patients in two major Rwandan teaching hospitals. The key finding was a high overall DVT prevalence of 5.5\% $(50 / 901)$ in the study population. Prevalence rates did not differ between medical and obstetrics-gynaecology patients, although some caution is advised in interpreting the risk among pregnant patients, who formed only $7 \%$ 
Table 3 Multivariable analysis of clinical and risk factors associated with DVT†

\begin{tabular}{|c|c|c|}
\hline Variable & OR $(95 \% \mathrm{Cl})$ & $\mathbf{P}$ value \\
\hline $\begin{array}{l}\text { Pain/tenderness of the } \\
\text { lower limb }\end{array}$ & 7.0 (2.4 to 20.3$)$ & $\leq 0.001^{*}$ \\
\hline Calf asymmetry $\ddagger$ & 3.6 (1.0 to 12$)$ & $0.042^{*}$ \\
\hline Entire limb swollen & 10 (4.1 to 24$)$ & $\leq 0.001^{*}$ \\
\hline $\begin{array}{l}\text { Unilateral limb pitting } \\
\text { oedema }\end{array}$ & 7.6 (2.3 to 26$)$ & $0.001^{*}$ \\
\hline $\begin{array}{l}\text { Tenderness along line of } \\
\text { femoral or popliteal veins }\end{array}$ & 0.70 (0.17 to 2.8$)$ & 0.605 \\
\hline $\begin{array}{l}\text { Dilated collateral superficial } \\
\text { veins }\end{array}$ & $1.6(0.20$ to 11$)$ & 0.666 \\
\hline Malignancy§ & 5.2 (2.0 to 13$)$ & $0.001^{*}$ \\
\hline Bedriddenף & $1.5(0.65$ to 3.7$)$ & 0.328 \\
\hline
\end{tabular}

*Statistically significant; $p<0.0 .05$.

†Only factors with a $p$ value $<0.05$ and an absolute frequency $>5$ were considered for multivariate analysis.

$\ddagger$ Calf more than $3 \mathrm{~cm}$ different in circumference, $10 \mathrm{~cm}$ below tibial tuberosity.

§Malignancy present or previous, on treatment or palliation up to 6 months previously.

IImmobilisation (complete bed rest or inability to walk for $>30 \mathrm{~min}$ per day) for $>3$ days.

DVT, deep vein thrombosis.

of the study population, and had a trend towards a higher rate of DVT overall $(11.4 \%, \mathrm{p}=0.09)$.

DVT occurrence was associated with malignancy, immobilisation, history of DVT, prolonged travel and use of DVT prophylaxis. Clinical features predictive of DVT on scanning included most recognised clinical symptoms and signs, such as unilateral pain or erythema, pitting oedema, calf asymmetry, distended superficial veins and tenderness along the femoral and popliteal veins. At least one of such features were present in more than $80 \%$ of diagnosed DVTs, pointing to the value of clinical diligence in making the diagnosis, and that most patients actually had symptomatic DVT, in contrast to many studies reporting such high prevalence, where asymptomatic distal DVTs often form the majority of diagnosed DVTs. Multivariate analysis identified active malignancy as a major independent risk factor for DVT, with clinical symptoms and signs of DVT unsurprisingly also remaining useful in predicting positive scan results.

The prevalence of proximal DVT in this study population was $5.5 \%$, this figure given that only proximal DVTs were screened for in our study, and only non-surgical patients were enrolled. Typically, in other recent studies with a comparably similar prevalence among medical patients, proximal and distal DVTs were included, and distal DVTs made up more than $80 \%$ of the observed thromboses. For example, in a French study where the prevalence of DVT in asymptomatic patients was 5.5\%, 11 out of 13 observed DVTs were distal. ${ }^{17}$ A German study with a similar methodology to ours, although only enrolling medical patients, reported a proximal DVT prevalence rate of $2.6 \% .^{22}$

Recent studies conducted retrospectively, and thus only considering symptomatic DVTs, generally report lower rates, in the range of $0.5 \%$ to $2 \%$ depending on the thromboprophylaxis uptake rates and the population studied. By way of illustration, a Chinese retrospective study showed a decreasing rate among medical inpatients across the period 2005 to 2008 , from $2 \%$ to $1.1 \%$, which the authors linked to greater thromboprophylaxis use in 2008. It should, however, be noted that smaller historical studies in the pre-thromboprophylaxis era among medical patients reported much high rates in the range of $10 \%$ to $30 \% .{ }^{23}$ The low observed rate of thromboprophylaxis use in our study, which is almost certainly linked to resource limitations, may thus form a major part of the explanation for the high observed prevalence. This low rate has been reported previously in a study of medical and surgical patients from across sub-Saharan Africa; only $25.9 \%$ of medical patients deemed at high risk in that study received appropriate thromboprophylaxis, suggesting the low observed rate of thromboprophylaxis in our study is representative of practice across the region. ${ }^{24}$ For example, despite high thromboprophylaxis rates, the DVT prevalence was $2.7 \%$ among a study of acutely ill medical-surgical patients admitted in intensive care unit $(\mathrm{ICU})^{25}$ and a German study reported a prevalence of $7.8 \%$ in a medical ICU cohort. ${ }^{26}$ In addition, Rwandan tertiary referral hospital medical patients, such as those enrolled in this study, typically include a large number of patients referred from district hospitals, who have often already had significant periods of hospitalisation prior to their admission to the tertiary centre. They thus form a selected population potentially at higher risk of DVT, and the rate observed may not be representative of that at smaller African hospitals. This should be a subject for further study.

The rate of DVT among the obstetrics-gynaecology patients in this study contrasts with an African study of pregnant Sudanese women at two tertiary hospitals in Khartoum, which showed a prevalence of $0.4 \%,{ }^{11}$ well below the rate of DVT evident in our study. The requirement for symptomatic DVT prior to enrolment in the Sudanese study had led to significant underdiagnosis of DVT in their study population, or it is possible that there is a major true difference in DVT prevalence among pregnant women, across different settings within Africa. This is deserving of further study, particularly as the rate observed in our study among pregnant women is alarmingly high. Some prior research has documented a rate of VTE in pregnant women around five times more than in the non-pregnant, ${ }^{12}$ and around a $1 \%-2 \%$ DVT risk after Caesarean section, ${ }^{27}$ with a high risk in the postpartum period. ${ }^{16}$ Our study, however, was not able to identify any significant association between pregnancy or the postpartum period and DVT, although this possibly could be due to a lack of power, given the 
small number of pregnant women enrolled. Literature also states that VTE in pregnant women is increased by smoking, prior VTE and inherited thrombophilia, ${ }^{13}$ but our ability to detect inherited thrombophilia was curtailed in this study by the unavailability of thrombophilia testing in Rwanda, which is a significant limitation of the study.

\section{DVT and sociodemographic characteristics}

Most patients in the current study were young, with people aged 60 and above accounting for only $17 \%$ of our study population. This largely reflects Rwanda's population pyramid, with only $3 \%$ of the population being over the age of 65 years. ${ }^{28}$ No significant differences in DVT rates were apparent on stratification by age, in contrast with Western studies which report that DVT is predominantly a disease of the middle aged and the elderly, with markedly increasing incidence with age. ${ }^{529}$ The clinically apparent high severity of illness in young patients enrolled in this study could mask the usual relationship of DVT and increasing age, but as our study did not collect data on illness severity, this is necessarily a matter of speculation until more research is conducted. Other studies from Africa have also reported a disproportionately high prevalence of DVT in the young, with a study from Ghana reporting the mean age of patient with DVT to be 32 , a fact the authors attributed to the sedentary lifestyle of young persons in their cohort, ${ }^{30}$ and another study from Kenya reporting the mean age for patients with VTE was 40.8 years (range, $5-86$ years). ${ }^{31}$ Likewise, there was no significant difference in DVT prevalence between women and men in our study, with prior research finding variably that either women were more affected ${ }^{29}$ or that there were no significant gender differences. ${ }^{10}$

In other populations, higher BMI has been identified as a risk factor for DVT, ${ }^{13} 32$ but we found no relationship between BMI and DVT in our study. There are several possible explanations for the lack of an observed relationship. First, obesity is uncommon in Rwanda, with the average BMI around 21, as described by Mutandwa, ${ }^{33}$ meaning our study is underpowered to detect any true difference. However, similar to other developing countries, in Rwanda, BMI have been increasing, especially in urban populations, ${ }^{33} 34$ so this may become more of an issue in the future. Furthermore, obesity is a risk factor for VTE particularly when OCPs are taken ${ }^{32}$ and only 7/632 women were taking OCPs in our study.

\section{DVT clinical features and risk factors}

Our results demonstrate that leg pain or tenderness, unilateral pitting oedema, femoral/popliteal vein tenderness and difference in calf circumference exceeding $3 \mathrm{~cm}$ were significantly associated with DVT occurrence on multivariate analysis. Oudega $e t$ al found similar clinical predictors of DVT among patients in the Netherlands: malignancy, dilated veins, oedema, swelling of the calf, swelling of the whole leg and difference in calf circumference. ${ }^{35}$ Various other studies from Western settings have criticised the clinical examination, deeming it to have little value in the diagnosis of DVT, ${ }^{135} 36$ but clinical symptoms and signs by far are the most powerful predictors of proximal DVT in our study. In Rwanda and many other subSaharan African settings, where access to compression ultrasonography is not necessarily available at every rural health centre, these clinical clues should still prove useful in raising clinicians' suspicion of DVT.

Risk factors including recent travel more than 6 hours, history of DVT, being bedridden and use of thromboprophylaxis were significantly associated with DVT on univariate analysis, but malignancy was the only significant risk factor for DVT from our multivariate analysis. Other predisposing factors such as leg trauma, acute infectious illness and congestive heart failure that have been identified as significant in other studies were not associated with DVT among Rwandan patients in our study, but many of these factors were rare, limiting our power and thus ability to draw definitive conclusions. The significant association between DVT and malignancy in our study with an OR of 5.2, are comparable with the Sirius study showing history of cancer or cancer progression as an intrinsic DVT risk factor (OR 2.33; $\mathrm{p}=0.001)^{10}$ and the MEDENOX study showing a statistically significant higher risk of VTE (OR 1.62) among medical patients with cancer. ${ }^{37}$

Acute infectious disease has been considered as a risk factor for DVT among medical inpatients in the MEDENOX study ${ }^{36}$ and Padua Risk assessment model, ${ }^{18}$ but it appeared to have no predictive power in our study population, with a trend towards a negative association evident. This is likely due to the different epidemiological profile of infectious illness in Africa, and points towards the need for unique DVT predictive tools to be developed for use in sub-Saharan Africa, a planned focus for our future efforts.

This study has several limitations. We relied on compression US scanning by non-radiologists to screen our patient population for DVT. This may have led to a systematic bias that underestimated the prevalence of proximal DVT in our study population. We had no access to venography, the preferred gold standard for confirming DVT, due to its lack of availability in Rwanda. Our cross-sectional study design with repeated sampling only enabled us to establish point prevalence of DVT but not the incidence of new events over time, which could be a focus for future research. Our analysis of many important subgroups was limited by the small numbers of patients in these groups, limiting our power to draw conclusions about many traditional risk factors. The study budget limited our potential sample size only to medical and obstetric-gynaecology inpatients, but we know that DVT is especially prevalent among surgical patients and future studies are needed in sub-Saharan Africa to evaluate the impact of DVT on the surgical patient population. Finally, we did not 
gather mortality data, and thus the clinical importance of our findings, in terms of the degree of morbidity and mortality resultant, can at this stage only be extrapolated from studies in other populations.

\section{CONCLUSION}

Proximal DVT prevalence is high among hospitalised medical and obstetric-gynaecology patients in two tertiary hospitals in Rwanda. Most of these DVTs were associated with clinical symptoms and signs that should have raised suspicion of DVT, with a current malignant diagnosis the main risk factor identified. Despite this, thromboprophylaxis use was low, with only $25 \%$ of our study population receiving any such therapy. For reducing morbidity and mortality, research to develop Africa-specific clinical prediction tools for DVT and interventions to increase thromboprophylaxis use in the region are urgently needed.

\section{Author affiliations}

${ }^{1}$ Internal Medicine, Rwamagana Hospital, Rwamagana, Eastern, Rwanda

${ }^{2}$ Internal Medicine, Butaro Hospital, Burera, Northern, Rwanda

${ }^{3}$ Internal Medicine, Centre Hospitalier Universitaire de Kigali, Kigali City, Rwanda

${ }^{4}$ College of Medicine and Health Sciences, University of Rwanda, Kigali, Rwanda

${ }^{5}$ School of Public Health, University of Texas, Houston, Texas, USA

${ }^{6}$ Warren Alpert Medical School, Brown University, Providence, Rhode Island, USA ${ }^{7}$ Internal Medicine, University of Goma, Goma, Nord-Kivu, Democratic Republic of the Congo

${ }^{8}$ Internal Medicine, Calvary Mater Newcastle, Hunter Region Mail Centre, New South Wales, Australia

${ }^{9}$ School of Medicine and Public Health, The University of Newcastle, Callaghan, New South Wales, Australia

Acknowledgements We acknowledge the interns, doctors and nurses in the Internal Medicine and Obstetrics-Gynecology Departments, as well as radiologists at CHUK and CHUB. Thank you especially to Matthew Cardillo for his contribution to data collection and entry.

Contributors RM, TDW, MS, KLL, SM, PLT, FM and EN conceptualised the research study. RM, ER and EN contributed to the acquisition of data. RM, KLL, MS and ER performed the statistical analysis. RM, SM, TDW and MS contributed to the interpretation of data, writing and editing the manuscript. All authors reviewed the manuscript for important intellectual content and approved the final version.

Funding The study was funded by the Swedish International Development Cooperation Agency (SIDA), under a University of Rwanda-Sweden Collaboration. The funding covered study materials such as ultrasound gel, paper, printing and travel for research staff from one site to another.

Disclaimer The funder of the study had no role in study design, data collection, data analysis, data interpretation or writing of the paper.

Competing interests None declared.

Patient consent for publication Obtained.

Ethics approval The study was approved by the Institutional Review Board of the College of Medicine and Health Sciences, University of Rwanda (CMHS/ IRB/64/2015). As the study was simultaneously conducted in two teaching hospitals, the Research and Ethics Committees of CHUK and CHUB and the Directors General of each hospital also approved the study.

Provenance and peer review Not commissioned; externally peer reviewed. Data availability statement Data are available on reasonable request.

Open access This is an open access article distributed in accordance with the Creative Commons Attribution Non Commercial (CC BY-NC 4.0) license, which permits others to distribute, remix, adapt, build upon this work non-commercially, and license their derivative works on different terms, provided the original work is properly cited, appropriate credit is given, any changes made indicated, and the use is non-commercial. See: http://creativecommons.org/licenses/by-nc/4.0/.

\section{ORCID iDs}

Regine Mugeni http://orcid.org/0000-0002-0434-8341

Timothy David Walker http://orcid.org/0000-0001-7034-1327

\section{REFERENCES}

1 Kesieme E, Kesieme C, Jebbin N, et al. Deep vein thrombosis: a clinical review. J Blood Med 2011;2:59-69.

2 Streiff MB, Brady PJ, Grant AM, et al. CDC grand rounds: preventing hospital-associated venous thromboembolism. Morb Mortal Wkly Rep 2014;63:190-3.

3 Stevens SM, Douketis JD. Deep vein thrombosis prophylaxis in hospitalized medical patients: current recommendations, general rates of implementation, and initiatives for improvement. Clin Chest Med 2010;31:675-89.

4 Naess IA, Christiansen SC, Romundstad P, et al. Incidence and mortality of venous thrombosis: a population-based study. J Thromb Haemost 2007;5:692-9.

5 Cushman M. Epidemiology and risk factors for venous thrombosis. Semin Hematol 2007;44:62-9.

6 Obalum DC, Giwa SO, Adekoya-Cole TO, et al. Deep vein thrombosis: risk factors and prevention in surgical patients. West Afr J Med 2009;28:77-82.

7 Cayley WE. Preventing deep vein thrombosis in hospital inpatients. BMJ 2007;335:147-51.

8 Lawall $\mathrm{H}$, Matthiessen A, Hohmann V, et al. Venous thromboembolism in medical outpatients - a cross-sectional survey of risk assessment and prophylaxis. Thromb Haemost 2011;105:190-6.

9 Danwang C, Temgoua MN, Agbor VN, et al. Epidemiology of venous thromboembolism in Africa: a systematic review. J Thromb Haemost 2017:15:1770-81.

10 Samama MM. An epidemiologic study of risk factors for deep vein thrombosis in medical outpatients: the Sirius study. Arch Intern Med 2000;160:3415-20.

11 Gader AA, Haggaz AED, Adam I. Epidemiology of deep venous thrombosis during pregnancy and puerperium in Sudanese women. Vasc Health Risk Manag 2009:5:85-7.

12 James AH, Tapson VF, Goldhaber SZ. Thrombosis during pregnancy and the postpartum period. Am J Obstet Gynecol 2005:193:216-9.

13 Anderson FA, Spencer FA. Risk factors for venous thromboembolism. Circulation 2003;107:I-9-I-16

14 Kasabe PS, Jaykar RD, Lakhpatre SB. A study of clinical profile of 50 patients with deep venous thrombosis at General Hospital. MedPulse - Int Med J 2014;1:676-80.

15 Kaplan D, Casper TC, Elliott CG, et al. VTE incidence and risk factors in patients with severe sepsis and septic shock. Chest 2015;148:1224-30.

16 Silveira PC, Ip IK, Goldhaber SZ, et al. Performance of wells score for deep vein thrombosis in the inpatient setting. JAMA Intern Med 2015;175:1112-7.

17 Oger E, Bressollette L, Nonent M, et al. High prevalence of asymptomatic deep vein thrombosis on admission in a medical unit among elderly patients. Thromb Haemost 2002;88:592-7.

18 Barbar S, Noventa F, Rossetto V, et al. A risk assessment model for the identification of hospitalized medical patients at risk for venous thromboembolism: the Padua prediction score. J Thromb Haemost 2010;8:2450-7.

19 Schmidt M, Horvath-Puho E, Thomsen RW, et al. Acute infections and venous thromboembolism. J Intern Med 2012;271:608-18.

20 Cogo A, Lensing AW, Koopman MM, et al. Compression ultrasonography for diagnostic management of patients with clinically suspected deep vein thrombosis: prospective cohort study. BMJ 1998;316:17-20.

21 Henwood PC, Mackenzie DC, Liteplo AS, et al. Point-of-care ultrasound use, accuracy, and impact on clinical decision making in Rwanda hospitals. J Ultrasound Med 2017;36:1189-94.

22 Lawall H, Hoffmanns W, Hoffmanns P, et al. Prevalence of deep vein thrombosis (DVT) in non-surgical patients at hospital admission. Thromb Haemost 2007:98:765-70.

23 Cohen AT, Alikhan R, Arcelus Jl, et al. Assessment of venous thromboembolism risk and the benefits of thromboprophylaxis in medical patients. Thromb Haemost 2005;94:750-9.

24 Kingue S, Bakilo L, Ze Minkande J, et al. Epidemiological African day for evaluation of patients at risk of venous thrombosis in acute hospital care settings. Cardiovasc J Afr 2014;25:159-64. 
25 Cook D, Crowther M, Meade M, et al. Deep venous thrombosis in medical-surgical critically ill patients: prevalence, incidence, and risk factors. Crit Care Med 2005;33:1565-71.

26 Lawall $\mathrm{H}$, Oberacker R, Zemmrich C, et al. Prevalence of deep vein thrombosis in acutely admitted ambulatory non-surgical intensive care unit patients. BMC Res Notes 2014;7:431.

27 Calderwood CJ, Thanoon OI. Venous thromboembolism in pregnancy. Obstet Gynaecol Reprod Med 2013;23:227-30.

28 National Institute of Statistics of Rwanda (NISR), Ministry of Finance and Economic Planning (MINECOFIN). Fourth population and housing census, Rwanda, 2012: thematic reports. Kigali-Rwanda 2014, 2014. http://www.statistics.gov. rw/publications/rphc4-all-thematic-reports

29 Fowkes FJI, Price JF, Fowkes FGR. Incidence of diagnosed deep vein thrombosis in the general population: systematic review. Eur $J$ Vasc Endovasc Surg 2003;25:1-5.

30 Aduful H, Darko R. Deep venous thrombosis of the lower limb in young ambulant Ghanaians. Ghana Med J 2007;41:17-20.

31 Ogeng'o JA, Obimbo MM, Olabu BO, et al. Pulmonary thromboembolism in an East African tertiary referral hospital. $J$ Thromb Thrombolysis 2011;32:386-91.
32 Abdollahi M, Cushman M, Rosendaal FR. Obesity: risk of venous thrombosis and the interaction with coagulation factor levels and oral contraceptive use. Thromb Haemost 2003;89:493-8.

33 Mutandwa E. An examination of socioeconomic determinants of average body mass indices in Rwanda. Open Obes $J$ 2015;7:1-9.

34 Amugsi DA, Dimbuene ZT, Mberu B, et al. Prevalence and time trends in overweight and obesity among urban women: an analysis of demographic and health surveys data from 24 African countries, 1991-2014 Dickson. Nat Commun 2013;4:1-12.

35 Oudega R, Moons KGM, Hoes AW. Limited value of patient history and physical examination in diagnosing deep vein thrombosis in primary care. Fam Pract 2005;22:86-91.

36 Tapson VF, Carroll BA, Davidson BL, et al. The diagnostic approach to acute venous thromboembolism. clinical practice guideline. American Thoracic Society. Am J Respir Crit Care Med 1999;160:1043-66.

37 Alikhan R, Cohen AT, Combe S, et al. Risk factors for venous thromboembolism in hospitalized patients with acute medical illness: analysis of the MEDENOX study. Arch Intern Med 2004;164:963-8. 